\title{
Modelling of the thermal conductivity in cold chain logistics based on micro-PCMs
}

\author{
Xuanxuan Zhang \\ College of Economics and Business Administration, Chongqing University, Chongqing 400044, China
}

Corresponding Author Email: jimmyzxx@ 126.com

https://doi.org/10.18280/ijht.360339

Received: 10 November 2017

Accepted: 30 May 20118

\section{Keywords:}

thermal conductivity, micro-PCMs, fractal theory, thermally conductive fluid

\begin{abstract}
This paper focuses on the thermal conductivity in cold chain logistics. Based on the basic theory of heat transfer, it improves the heat transfer performance of micro-PCMs by adding thermally conductive fluid into micro-PCMs, and then analyzes the change in the thermal conductivity before and after improvement as well as the cold storage speed and temperature control performance after the addition of the thermally conductive fluid. In addition, it also establishes an effective thermal conductivity model for the dispersion system based on the fractal theory. The results show that the effective thermal conductivity of micro-PCMs increases with the increasing volume of thermally conductive fluid added. When the volume fraction reaches about $50 \%$, the increase of the effective thermal conductivity significantly slows down. Through model analysis, it is concluded that the effective thermal conductivity of the dispersion system cannot be accurately characterized without considering the gas phase influences, and that the simulated value considering the gas phase influences is consistent with the test value. Through test analysis and numerical modelling, it is found that the optimal volume fraction of thermally conductive fluid in micro-PCMs is between $36-40 \%$. This study provides theoretical support for the heat transfer system of micro-PCMs in cold chain logistics.
\end{abstract}

\section{INTRODUCTION}

With people's expectations for living standards continuously rising, the transportation of various temperaturesensitive products, such as fresh foods, medicines and biological products, is constantly expanding, and also becoming increasingly challenging in terms of cold storage [12]. To make cold chain logistics safer and more reliable, lowcost, efficient and convenient, further research is required in this field. Considering the importance of cold chain logistics, ISTA proposed the test method and standards for cold chain transportation and packaging in 2010. Chinese authority proposed in 2014 a variety of measures to accelerate the development of cold chain logistics and transportation, but the key constraint on the temperature control technology of logistics is the lack of research on the phase change thermal conductivity theory of temperature-controlled cold chain transportation, which makes it difficult to accurately control the temperature and time of the refrigerating chamber in cold chain transportation in practice [3]. Being temperaturesensitive, phase change materials absorb the heat transferred from the external environment to the insulated container to control temperature and ensure the heat transfer efficiency in cold chain logistics. Based on this, it is essential to study the main performance and parameters of phase change materials (PCMs) [4]. The study of its main properties and the study of the main performance parameters are very important. This paper mainly studies the thermal conductivity of phase change materials to characterize the heat transfer capacity of the PCMs between different materials.

The phase change process of PCMs is between isothermal and approximate isothermal processes, accompanied by the exchange of energy substances. This process is completely reversible and can be recycled [5]. The recently developed microcapsule technology is to capsulate solid and liquid together with film-forming materials to form solid particles [6]. With the aid of this technology, the microcapsule phase change materials (micro-PCMs) of coolant obtained can prevent PCMs from reacting with surrounding substances, control the volume change during the phase transformation, and improve the material use efficiency. Based on the characteristics of micro-PCMs, there are a great number of studies at home and abroad on the PCMs, trying to provide some directions for the optimization of PCMs in cold chain logistics [7], but the variation characteristics of the PCMs during transportation still require further research. Based on the previous research results of thermodynamics and PCMs in cold chain transportation, this paper performs characterization analysis of the thermal conductivity of micro-PCMs in cold chain logistics, with a view to providing new ideas and directions for further research in this field [8].

\section{PERFORMANCE OPTIMIZATION OF THE THERMAL CONDUCTIVITY AND CHARACTERIZATION ANALYSIS AFTER OPTIMIZATION}

\subsection{Test materials and methods}

Test materials: the wall material of micro-PCMs is thin, which has little impact on density and thermal conductivity, so this material can be neglected. Pure water is selected as the continuously thermally conductive fluid. In order to prevent precipitation of solids, the pure water is added with $2 \% \mathrm{CMC}$ thickener. The Micro-PCMs are used as the coolant. The 
physical parameters of the test materials are listed in Table 1 below.

Table 1. Test materials and coefficients

\begin{tabular}{cccc}
\hline Materials & $\rho / \mathrm{kg} / \mathrm{m} 3$ & $\mathrm{~K} / \mathrm{W} /(\mathrm{m} . \mathrm{K})$ & $\mathrm{L} / \mathrm{kJ} / \mathrm{Kg}$ \\
\hline Water \& CMC & 996.6 & 0.612 & $\mathrm{~N} / \mathrm{A}$ \\
Micro-PCMs & 891 & 0.468 & 110.3 \\
\hline
\end{tabular}

Main testing equipment and instruments: constant temperature and humidity chamber, thermal conductivity meter, scanning electron microscope, thermal conductivity determinator and particle size analyzer, etc.

Preparation of test materials and methods:

(1) Prepare 20 samples: weigh micro-PCM samples with a mass fraction of $3 \%, 8 \%, 13 \%, 18 \%, 23 \%, 28 \%, 33 \%, 38 \%$, $43 \%, 48 \%, 53 \%, 58 \%, 63 \%, 68 \%, 73 \%, 78 \%, 83 \%, 88 \%, 93 \%$ and $100 \%$, respectively, add water with an appropriate mass fraction and $2 \% \mathrm{CMC}$, stir them well and at the same time add $2 \% \mathrm{CMC}$ into deionized water as control samples.

(2) After the samples are vacuum treated, place them in the constant temperature and humidity chamber for 24 hours.

(3) Measure the thermal conductivity of samples using the DQCS thermal conductivity meter; determine the latent heat

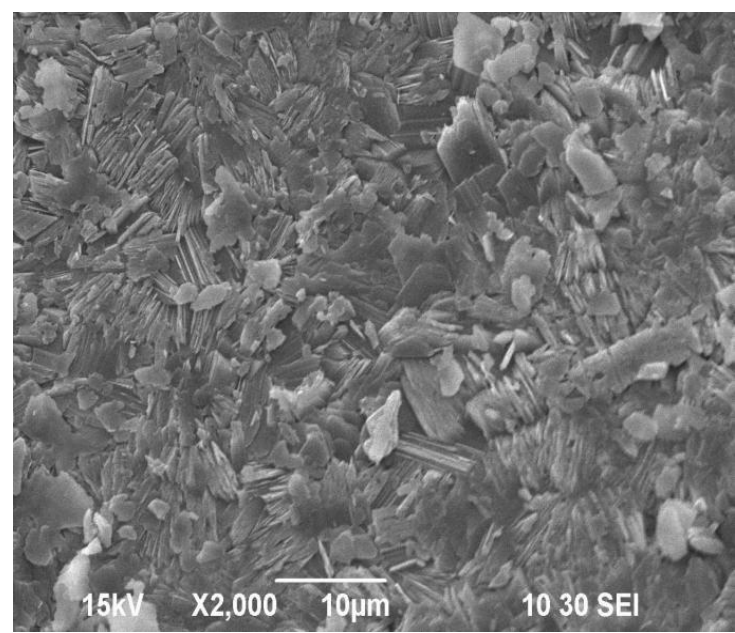

of sample phase changes with the thermal gravimetric analyzer; observe the microscopic morphology of sample micro-PCMs after immersion in the thermally conductive fluid using the SEM electron microscopy and apply the EQPC particle size analyzer to determine the dispersed phase particle size ratio and the particle size distribution; measure the mass and volume of the samples with an electronic balance (with a precision of 0.000 ) and a graduated cylinder; calculate the sample density with the data, measure each group of samples 4 times and finally take the average.

\subsection{Characterization analysis of the optimized thermal conductivity}

After the micro-PCMs are mixed with the thermally conductive fluid, the state formed is called a dispersed phase. Since the thermally conductive fluid is a continuous phase dispersion system, the relationship between the volume, mass fraction and apparent density of the thermally conductive fluid is significantly correlated with the volume fraction of the thermally conductive particles mixed in the PCMs. The test results are listed in Table 2 and Fig.1-3.

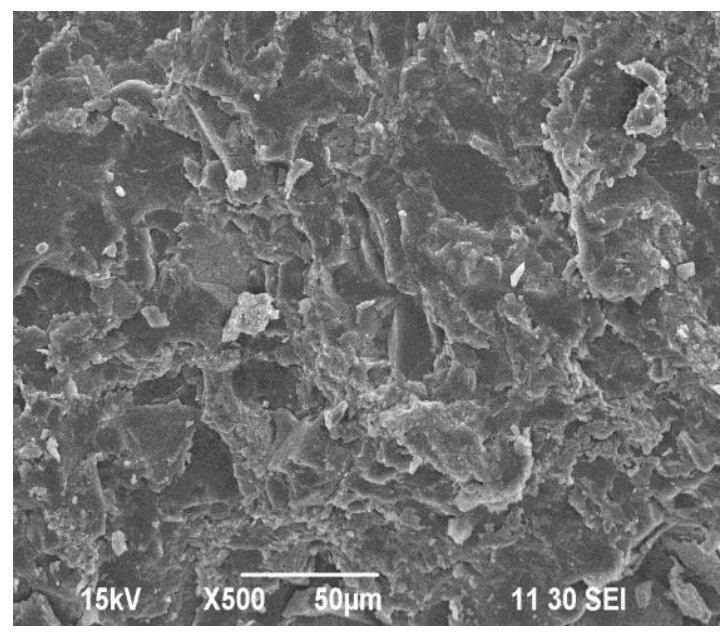

Figure 1. Microstructure after addition of thermal conductive fluid

The observation results of the scanning electron microscope in Fig. 1 indicate that after the thermally conductive fluid is added into the micro-PCMs, the particles are evenly distributed, with obviously regular shapes. The particle size is uniform, ranging from 3.6 to 6 , and the particle size ratio is 0.42 . From this, it can be seen that the particles are uniformly distributed and good for heat transfer. This greatly supports the effective thermal conductivity.

Table 2. Analysis of test results

\begin{tabular}{cccccccc}
\hline $\begin{array}{c}\text { Mass } \\
\text { fraction }\end{array}$ & $\begin{array}{c}\text { Apparent } \\
\text { density }\end{array}$ & $\begin{array}{c}\text { Dispersed } \\
\text { phase }\end{array}$ & $\begin{array}{c}\text { Thermal } \\
\text { conductivity }\end{array}$ & $\begin{array}{c}\text { Mass } \\
\text { fraction }\end{array}$ & $\begin{array}{c}\text { Apparent } \\
\text { density }\end{array}$ & $\begin{array}{c}\text { Dispersed } \\
\text { phase }\end{array}$ & $\begin{array}{c}\text { Thermal } \\
\text { conductivity }\end{array}$ \\
\hline $3 \%$ & 981 & 0.03 & 0.66 & $53 \%$ & 585 & 0.46 & 0.35 \\
$8 \%$ & 952 & 0.06 & 0.62 & $58 \%$ & 527 & 0.47 & 0.29 \\
$13 \%$ & 938 & 0.09 & 0.61 & $63 \%$ & 482 & 0.45 & 0.26 \\
$15 \%$ & 932 & 0.14 & 0.59 & $68 \%$ & 468 & 0.43 & 0.22 \\
$23 \%$ & 895 & 0.22 & 0.63 & $73 \%$ & 439 & 0.41 & 0.19 \\
$28 \%$ & 825 & 0.29 & 0.67 & $78 \%$ & 428 & 0.39 & 0.17 \\
$33 \%$ & 803 & 0.35 & 0.66 & $83 \%$ & 415 & 0.41 & 0.13 \\
$38 \%$ & 735 & 0.42 & 0.61 & $88 \%$ & 392 & 0.38 & 0.12 \\
$43 \%$ & 694 & 0.45 & 0.48 & $93 \%$ & 383 & 0.37 & 0.09 \\
$48 \%$ & 652 & 0.43 & 0.42 & $100 \%$ & 378 & 0.38 & 0.11 \\
\hline
\end{tabular}




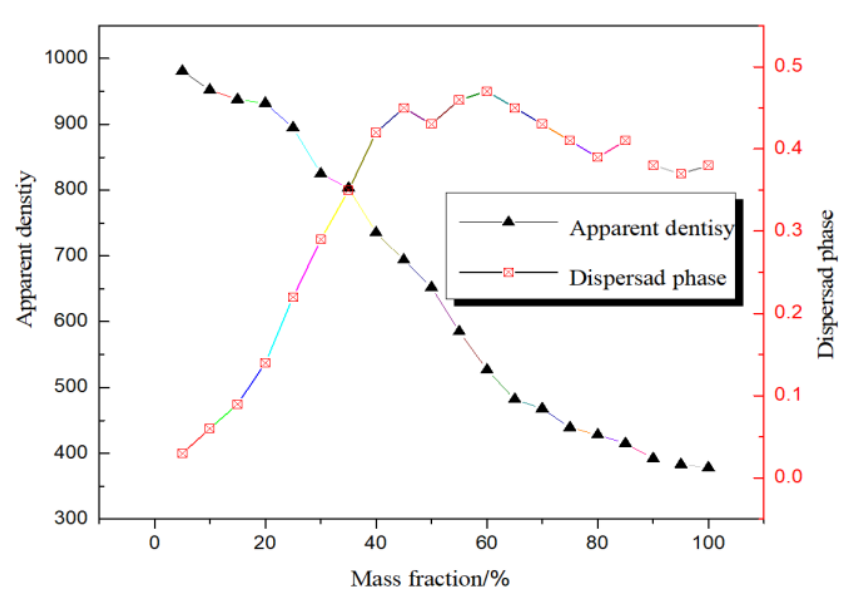

Figure 2. Density of heterogeneous materials and dispersed phase volume fraction under different dispersed phase weight fractions

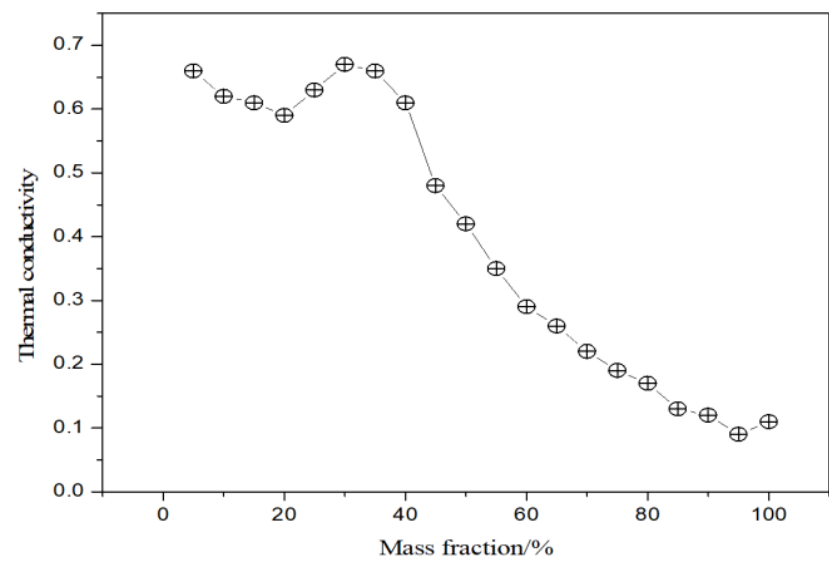

Figure 3. Effective thermal conductivity of heterogeneous materials under different dispersed phase weight fractions

According to the trend in Fig. 2-3 and the data in Table 2, when the mass fraction is small, the apparent density shows a slow decline with the increase of the mass fraction. When the mass fraction reaches about $40 \%$, the apparent density decreases rapidly, and the volume fraction starts to stabilize at a certain value. At the same time, since the active component of the coolant used in the test is micro-PCM particles, the addition of the heat transfer fluid significantly affects the latent heat of phase change due to the heat transfer between objects. The test analyzes the variation pattern of the phase change thermal conductivity of mixed micro-PCMs with different dispersed phase mass fractions, as shown in Fig.3. The phase change thermal conductivity of the mixed micro-PCMs increases approximately linearly with the increase of the mass fraction of the thermally conductive fluid. However, with the proportion of the thermally conductive fluid added reaches $40 \%$, the thermal conductivity starts to show a downward trend, so the amount of the thermally conductive fluid added into the micro-PCMs should not be too much; otherwise, the phase change thermal conductivity will decrease.

\section{EFFECTIVE THERMAL CONDUCTIVITY MODELLING METHOD AND ANALYSIS}

The above test analysis shows that for the same amount of micro-PCMs, changing the volume fraction of the thermally conductive fluid can significantly increase its effective thermal conductivity, but the limitation of the test is that it assumes the temperature is a set value, so the effect on temperature control time is not significant. Regarding this, adding appropriate amount of thermally conductive fluid to increase the effective thermal conductivity of PCMs can shorten the cold storage cycle of the PCMs and thus facilitate their use [9]. In order to accurately control the effective thermal conductivity of the optimized micro-PCMs, and study the control characteristics of the effective thermal conductivity at different temperatures, it is necessary to further explore the mathematical model characterizing the control relationships between the doping amount in the PCM, the effective thermal conductivity and the thermal conductivities at different temperatures.

\subsection{Performance optimization pattern analysis of the thermal conductivity}

The micro-PCM studied in this paper is a micro-particle high-dispersion system. To accurately describe its effective thermal conductivity, the gas phase influences in the dispersion system should be considered. The existing literatures and theoretical models still cannot describe the effective thermal conductivity of the solid-liquid-gas dispersion system [10-11], so this paper proposes an effective thermal conductivity model for the micro-PCM dispersion system with different mass fractions [12]. The modelling method is shown in Fig. 4. The theoretical calculation equation for thermal conductivity is based on the simulation steps of the MEI model under the micro-particle mass fraction in the literature.

When the volume fraction of the micro-particles is lower than the saturation value, the dispersion system consists of the solid phase and the liquid phase. When the volume fraction of the micro-particles reaches the saturation value, the dispersion system contains solid, liquid, and gas phases. In the dispersion system structure with these three phases, the components with high thermal conductivity can form a continuous medium in the heat transfer direction, which facilitates heat transfer, and the system has a high thermal conductivity. Even if the gas phase is mixed into the system, the effective thermal conductivity of the system will not drop significantly. This paper simulates the variation curves of the internal temperature with time at different storage temperatures, and the influences of the thermal conductivity of the PCM on thermal resistance. Based on the above modelling method, the results of the model considering and without considering the liquid phase are compared with the experimental data, as shown in Fig.5 and table 3. 


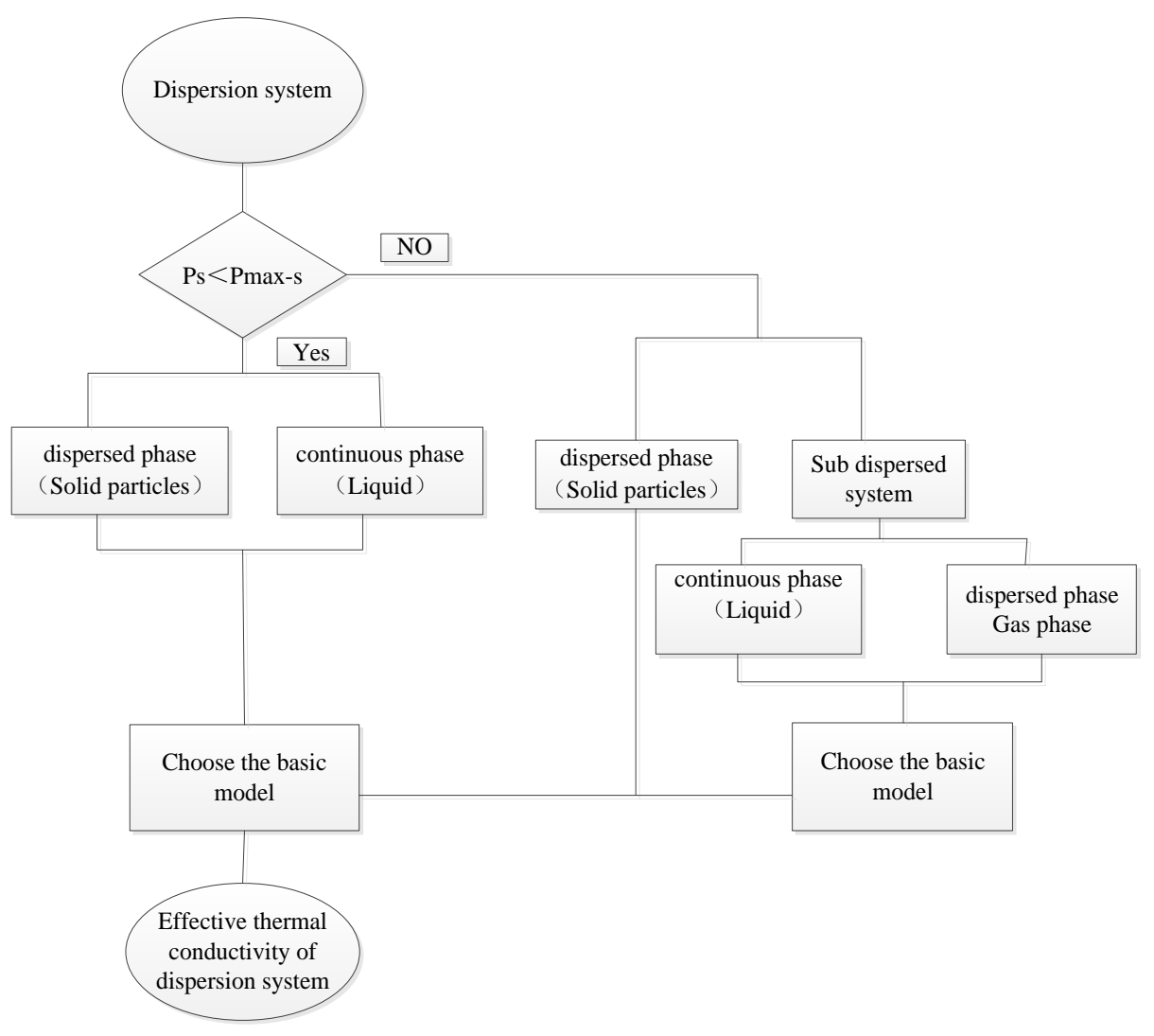

Figure 4. General modelling procedure for predicting the effective thermal conductivity of heterogeneous materials

Table 3. The gas phase is compared with the experimental value without considering the gas phase simulation results

\begin{tabular}{cccccccc}
\hline $\begin{array}{c}\text { mass } \\
\text { fraction }\end{array}$ & $\begin{array}{c}\text { Experimental } \\
\text { Vaule }\end{array}$ & $\begin{array}{c}\text { Gas-phase } \\
\text { Consideration }\end{array}$ & Not consider gas-phase & $\begin{array}{c}\text { mass } \\
\text { fraction }\end{array}$ & $\begin{array}{c}\text { Experimental } \\
\text { Vaule }\end{array}$ & $\begin{array}{c}\text { Gas-phase } \\
\text { Consideration }\end{array}$ & Not consider gas- phase \\
\hline $3 \%$ & 0.66 & 0.61 & 0.61 & $53 \%$ & 0.35 & 0.36 & 0.43 \\
$8 \%$ & 0.62 & 0.63 & 0.58 & $58 \%$ & 0.29 & 0.32 & 0.42 \\
$13 \%$ & 0.61 & 0.56 & 0.56 & $63 \%$ & 0.26 & 0.26 & 0.43 \\
$15 \%$ & 0.59 & 0.55 & 0.51 & $68 \%$ & 0.22 & 0.22 & 0.43 \\
$23 \%$ & 0.63 & 0.59 & 0.49 & $73 \%$ & 0.19 & 0.19 & 0.43 \\
$28 \%$ & 0.67 & 0.58 & 0.44 & $78 \%$ & 0.17 & 0.17 & 0.42 \\
$33 \%$ & 0.66 & 0.56 & 0.43 & $83 \%$ & 0.13 & 0.12 & 0.42 \\
$38 \%$ & 0.61 & 0.51 & 0.42 & $88 \%$ & 0.12 & 0.11 & 0.43 \\
$43 \%$ & 0.48 & 0.48 & 0.43 & $93 \%$ & 0.09 & 0.12 & 0.42 \\
$48 \%$ & 0.42 & 0.42 & 0.43 & $100 \%$ & 0.11 & 0.11 & 0.42 \\
\hline
\end{tabular}

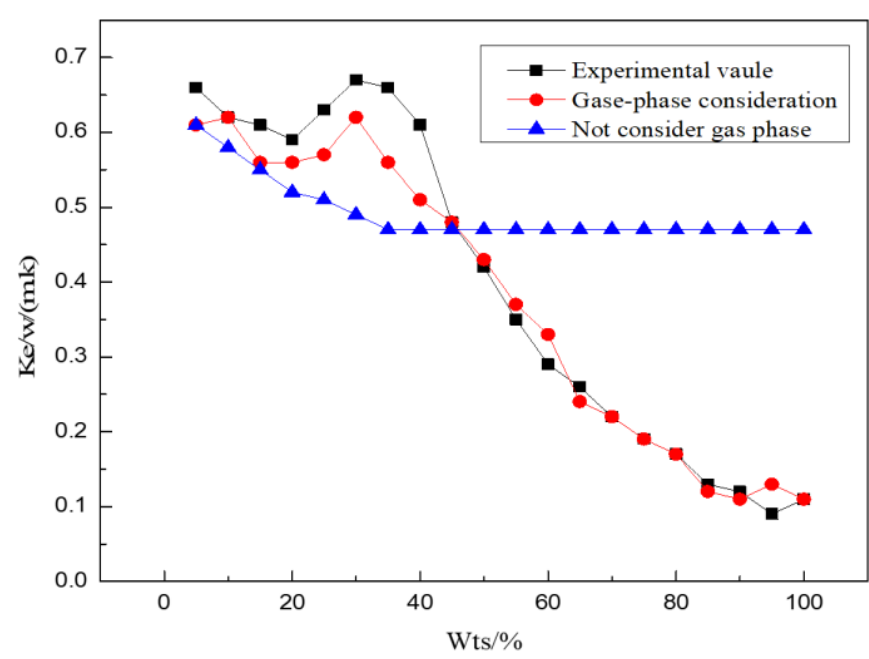

Figure 5. Test curves of effective thermal conductivity compared to the model results

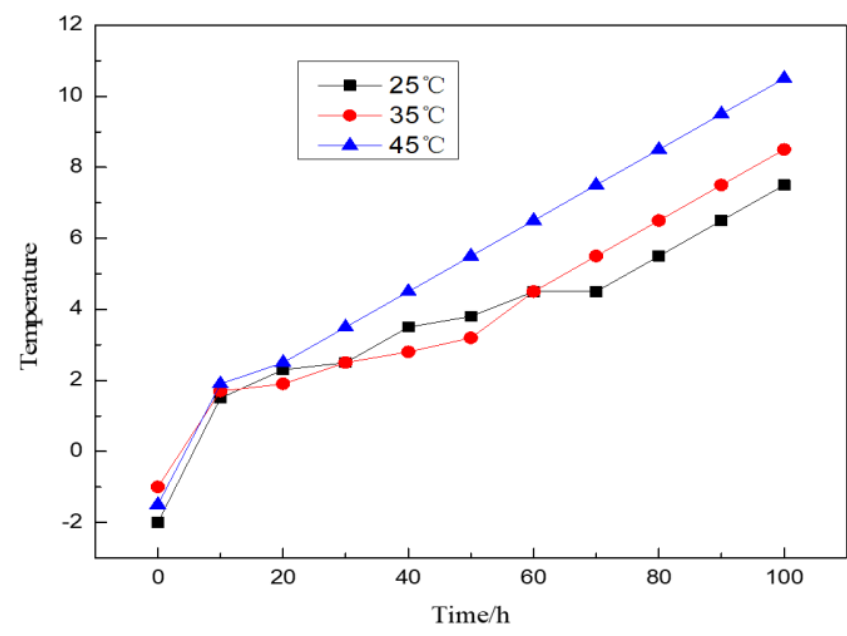

Figure 6. Characteristics of the thermal conductivity at different temperatures 
The simulated trends in Fig. 5 show that the experimental values of the thermal conductivity of micro-PCMs are consistent with those of the model considering the liquid phase and have certain deviations from those of the model without considering the liquid phase. Therefore, the design of the coolant in the cold chain logistics process should take the impacts of the gas phase and the liquid phase into account.

The test assumes that the temperature is a constant value to test the thermal conductivity of the micro-PCMs, so there is a certain deficiency in the measurement of the actual thermal conductivity. Therefore, based on the above model, the simulation is performed under different temperature conditions. The thermal conductivity comparison results are shown in Fig. 6.

\subsection{Characteristics analysis of the effective thermal conductivity based on the fractal theory}

At different concentrations, the solid particles in the dispersion system will be irregularly distributed, and the particles will collide with each other. These colliding particles will form a series of intermittent heat conduction channels, so the dispersion and heat conduction under different concentrations of solid particles can be understood as the heat conduction in irregular channels [13-14]. To solve the above problem in thermal conductivity, this paper uses the fractal theory, which is often used to describe the geometric features of irregular structures, and also the seepage theory, which is the basic theory for describing the irregular flow of matters (or energy) in irregular channels [15]. After improving the thermal conductivity of the PCMs by adding the thermally conductive fluid into the solid-phase micro-PCMs, this paper studies whether the variation pattern of the thermal conductivity of the micro-PCMs with the addition of the thermally conductive fluid has anything to do with the distribution of the particles, and then proposes a modeling method for the effective thermal conductivity of the dispersion system with a high mass fraction of solid particles and establishes a prediction model for the effective thermal conductivity of the dispersion system based on the fractal theory and the seepage theory. The results show that the model can effectively predict the effective thermal conductivity of the dispersion system. The results of the fractal model are compared with the experimental values and the prediction results of the MEI model, as shown in Fig. 7 and table 4 .

Table 4. The simulation values of different models are compared with the experimental values

\begin{tabular}{cccccccc}
\hline $\begin{array}{c}\text { mass } \\
\text { fraction }\end{array}$ & $\begin{array}{c}\text { Experimental } \\
\text { Vaule }\end{array}$ & $\begin{array}{c}\text { Practal } \\
\text { Modle }\end{array}$ & $\begin{array}{c}\text { Fractal } \\
\text { Modle }\end{array}$ & $\begin{array}{c}\text { mass } \\
\text { fraction }\end{array}$ & $\begin{array}{c}\text { Experimental } \\
\text { Vaule }\end{array}$ & $\begin{array}{c}\text { Practal } \\
\text { Modle }\end{array}$ & $\begin{array}{c}\text { Fractal } \\
\text { Modle }\end{array}$ \\
\hline $3 \%$ & 0.66 & 0.61 & 0.60 & $53 \%$ & 0.35 & 0.36 & 0.33 \\
$8 \%$ & 0.62 & 0.63 & 0.63 & $58 \%$ & 0.29 & 0.32 & 0.26 \\
$13 \%$ & 0.61 & 0.56 & 0.55 & $63 \%$ & 0.26 & 0.22 & 0.19 \\
$15 \%$ & 0.59 & 0.55 & 0.57 & $68 \%$ & 0.22 & 0.17 \\
$23 \%$ & 0.63 & 0.59 & 0.59 & $73 \%$ & 0.19 & 0.19 \\
$28 \%$ & 0.67 & 0.58 & 0.54 & $78 \%$ & 0.17 & 0.12 \\
$33 \%$ & 0.66 & 0.56 & 0.50 & $83 \%$ & 0.13 & 0.11 \\
$38 \%$ & 0.61 & 0.51 & 0.49 & $88 \%$ & 0.12 & 0.12 \\
$43 \%$ & 0.48 & 0.48 & 0.48 & $93 \%$ & 0.09 & 0.11 \\
$48 \%$ & 0.42 & 0.42 & 0.45 & $100 \%$ & 0.11 & 0.12 \\
\hline
\end{tabular}

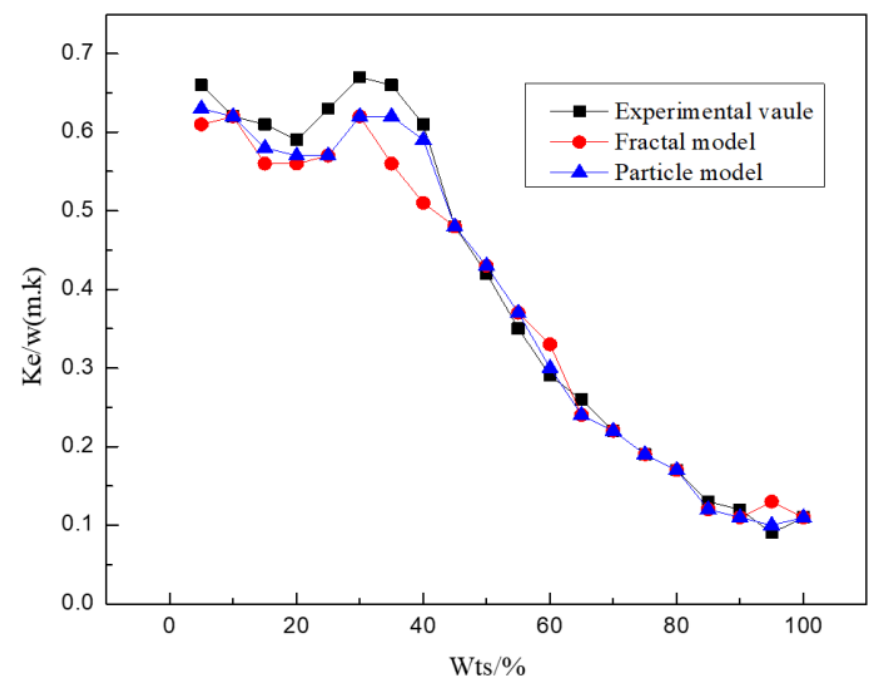

Figure 7. Different models are compared with experimental values

The thermal conductivity simulation results of the fractal model show a pattern like the experimental values, indicating that this model can be used to effectively predict the thermal conductivity of the dispersion system. This result is of great guiding significance to the optimization of the particle distribution and heat transfer distribution for the micro-PCMs with improved thermal conductivity.

\section{CONCLUSIONS}

(1). Adding thermally conductive fluid to micro-PCMs can optimize its thermal conductivity, but the mass fraction of the thermally conductive fluid should not be too high - preferably between $36-40 \%$, and the ambient temperature should not be over $45^{\circ} \mathrm{C}$;

(2). By establishing the MEI and fractal-theory-based models, this paper studies the effects of the gas phase on micro-PCMs, which can help predict the effective thermal conductivity of the dispersion system.

(3). The surface thermal conductivity and the interface moving speed change with the ambient temperature under the variable temperature environment. Further study of the particle shape, particle size and particle size ratio and its application in the system is the key to the characterization of thermal conductivity.

\section{REFERENCES}

[1] Petrasch J, Meier F, Friess H, Steinfeld A. (2008). Tomography based determination of permeability, 
dupuit-forchheimer coefficient, and interfacial heat transfer coefficient in reticulate porous ceramics. International Journal of Heat \& Fluid Flow 29(1): $315-$ 326.

http://dx.doi.org/10.1016/j.ijheatfluidflow.2007.09.001

[2] Hagishima A, Tanimoto J. (2003). Field measurements for estimating the convective heat transfer coefficient at building surfaces. Building \& Environment 38(7): 873881. http://dx.doi.org/10.1016/S0360-1323(03)00033-7

[3] Jung DS, Mclinden M, Radermacher R, Didion D. (1989). A study of flow boiling heat transfer with refrigerant mixtures. International Journal of Heat \& Mass Transfer 32(9): 1751-1764. http://dx.doi.org/10.1016/0017-9310(89)90057-4

[4] Song HL, Yong YU. (2007). Application of security monitoring in agricultural products cold-chain logistics. Logistics Technology 26: 177-180.

[5] Kuo WS, Lie YM, Hsieh YY, Lin TF. (2005). Condensation heat transfer and pressure drop of refrigerant $\mathrm{r}-410 \mathrm{a}$ flow in a vertical plate heat exchanger. International Journal of Heat \& Mass Transfer 48(25): 5205-5220.

http://dx.doi.org/10.1016/j.ijheatmasstransfer.2005.07.0 23

[6] Darzi M, Sadoughi MK, Sheikholeslami M. (2018). Condensation of nano-refrigerant inside a horizontal tube. Physica B Condensed Matter, 537, 33-39. http://dx.doi.org/10.1016/j.physb.2018.02.002

[7] Jr PCW, Kao YK, Lacroix LV. (1976). The interline heat-transfer coefficient of an evaporating wetting film. International Journal of Heat \& Mass Transfer 19(5): 487-492. http://dx.doi.org/10.1016/00179310(76)90161-7

[8] Hou Q, Sun J. (2018). Carbon reduction technology investment of supply chain under quota trading and government subsidy. Chemical Engineering Transactions 66: 529-534. http://dx.doi.org/10.3303/CET1866089
[9] Bhagoria JL, Saini JS, Solanki SC. (2002). Heat transfer coefficient and friction factor correlations for rectangular solar air heater duct having transverse wedge shaped rib roughness on the absorber plate. Renewable Energy 25(3): 341-369. http://dx.doi.org/10.1016/S09601481(01)00057-X

[10] Koçyigit N, Bulgurcu H. (2018). Modeling of overall heat transfer coefficient of a concentric double pipe heat exchanger with limited experimental data by using curve fitting and artificial neural network combination. Thermal Science 111-111. http://dx.doi.org/10.2298/TSCI171206111K

[11] Wang S, Tao F, Shi Y. (2018). Optimization of locationrouting problem for cold chain logistics considering carbon footprint. International Journal of Environmental Research \& Public Health 15(1): 86. http://dx.doi.org/10.3390/ijerph15010086

[12] Qi L, Xu M, Fu Z, Mira T, Zhang X. (2014). C2 slds: a wsn-based perishable food shelf-life prediction and lsfo strategy decision support system in cold chain logistics. Food Control 38(1): 9-29. http://dx.doi.org/10.1016/j.foodcont.2013.09.023

[13] Yan Z, Zhang WT, Yi W, Xin Z, Li L, Zhao QX. (2013). Development and application of time-temperature indicators used on food during the cold chain logistics. Packaging Technology \& Science 26(S1): 80-90. http://dx.doi.org/10.1002/pts.2009

[14] Jin SN, Xiao GS, Zhang YS, Ji-Jun WU, Ding CJ. (2008). Analysis of cold chain logistics and its present application in food industry. Modern Food Science \& Technology 36(E1): 115-119

[15] Xiao X, He Q, Li Z, Antoce AO, Zhang X. (2017). Improving traceability and transparency of table grapes cold chain logistics by integrating WSN and correlation analysis. Food Control 73(part B): 1556-1563. http://dx.doi.org/10.1016/j.foodcont.2016.11.019 